2. Ложкин А.Г., Каюкова О.В., Нестерова О.П. Экологическое испытание сортов яровой твердой пшеницы в агроклиматических условиях Чувашской Республики // Агроэкологические и организационно-экономические аспекты создания и эффективного функционирования экологически стабильных территорий: материалы Всерос. науч.-практ. конф. - Чебоксары, 2017. - С. 101-104.

3. Ложкин А.Г., Димитриев В.Л., Елисеев И.П. Яровая твердая пшеница в Чувашской Республике // Вестник Чувашской государственной сельскохозяйственной академии. - 2017. - № 3 (3). - С. 22-26.

4. Мальчиков П.Н., Вьюшков А.А., Мясникова М.Г. Формирование моделей сортов твердой пшеницы для Средневолжского региона России. - Самара: СамНЦ РАН, 2012. - 112 с.

5. Мальчиков П.Н., Мясникова М.Г. Сорта яровой твердой пшеницы для Средневолжского и Уральского регионов Российской Федерации // Достижения науки и техники АПК. - 2015. - Т. 29. - № 10. - С. 58-62.

6. Производство высококачественного зерна яровой твердой пшеницы в Среднем Поволжье / С.Н. Шевченко [и др.] // Научно практическое руководство; Самарский НИИСХ. - Самара: СамНЦ РАН, 2010. - 75 с.

7. Cапега B.A., Турсумбекова Г.Ш. Продуктивность и параметры адаптивности сортов твердой яровой пшеницы // Аграрная наука. - 2013. - № 9. C. $12-14$

8. Технология возделывания яровой твердой пшеницы с применением препаратов Секатор турбо, Баритон, Фалькон, Нагро и других / Ю.Я. Спиридонов [и др.] // Аграрный научный журнал. - 2017. - № 3. - С. 30-36.

Ложкин Александр Геннадьевич, канд. с.-х. наук, доцент кафедры «Земледелие, растениеводство, селекция и семеноводство», Чувашская государственная сельскохозяйственная академия. Россия.

428003, г. Чебоксары, ул. К. Маркса, 29.

Тел.: 89278629681.

Мальчиков Петр Николаевич, $\partial-p$ c.- $x$. наук, зав. лабораторией селекции яровой твердой пшеницы, Самарский научно-исследовательский институт сельского хозяйства имени Н.М. Тулайкова. Россия.

446254, Самарская обл., Безенчукский p-н, п.г.т. Безенчук, ул. К. Маркса, 41.

Тел: (84676) 2-11-40.

Ключевые слова: яровая твердая пшеница; сорта; сортоиспытание; высота растений; кустистость; масса семян; количество зерен; урожайность.

\title{
THE PRODUCTIVITY OF CULTIVARS OF SPRING DURUM WHEAT IN THE CHUVASH REPUBLIC
}

Lozhkin Alexander Gennadievich, Candidate of Agricultural Sciences, Associate Professor of the chair "Agriculture, Plant Growing, Selection and Seed Production", Chuvash State Agricultural Academy. Russia.

Malchikov Pyotr Nikolaevich, Doctor of Agricultural Sciences, Head of the laboratory of plant breeding of spring durum wheat, Samara Research Institute of Agriculture named after N.M. Tulaykov. Russia.

Keywords: spring durum wheat; varieties; variety testing; plant height; bushiness; seed weight; number of grains; yield.

The article presents experimental data of spring hard wheat variety tests in the agro-climatic conditions of the Chuvash Republic in 2015 and 2017. The results of biometric analysis of spring durum wheat plants showed that the height of plants by variety averaged over two years was from 74.55 to $104.75 \mathrm{~cm}$. The most marked low-growing variety bezenchukskaya 200, the highest plant was observed in cultivar bezenchukskaya 205. The best indicators of productive tilling capacity identified in the variety bezenchukskaya Niva and bezenchukskaya 209. The best indicators of crop structure recorded in the variety bezenchukskaya the field, where the length of the ear was $5.1 \mathrm{~cm}$, number of seeds per spike of 22.9 units, and weight of seeds per spike to $1.12 \mathrm{~g}$. the Lowest annual rates were observed in cultivar bezenchukskaya 205, number of seeds per spike of $16.8 \mathrm{PC}$, and the seed weight was $0.76 \mathrm{~g}$. It was found out that the number and weight of grains in the ear depending on the variety varied in proportion to the length of the ear. The weight of 1000 seeds ranged from 42.32 to 53.27 grams. Accounting of biological yield revealed the advantage of Bezenchukskaya Niva-34.1 t/ha, the lowest yield of 19.6t / ha formed Bezenchukskaya 205.

\section{DOI \\ УдК 591.3:59.085 \\ ВЛИЯНИЕ УСЛОВИЙ ЭКВИЛИБРАЦИИ НА ЖИЗНЕСПОСОБНОСТЬ ВИТРИФИЦИРОВАННЫХ ООЦИТОВ КОРОВ}

\author{
МАЛЕНКО Галина Петровна, ФГБНУ Центр экспериментальной эмбриологии и репродуктивных \\ биотехнологий
}

РОМАНОВА Анастасия Борисовна, ФГБНУ Центр экспериментальной эмбриологии и репродуктивных биотехнологий

БРИГИДА Артем Владимирович, ФГБНУ Центр экспериментальной эмбриологии и репродуктивных биотехнологий

КОРНИЕНКО Екатерина Валерьевна, ФГБНУ Центр экспериментальной эмбриологии и репродуктивных биотехнологий

Представлены результаты оценки влияния условий эквилибрации на жизнеспособность дозревщих іn vitro ооцитов крупного рогатого скота после витрификации в триацетатиеллюлозных полых волокнах. Полуиенные результаты свидетельствуют о том, что одним из факторов, положительно влияющих на выживание ооцитов КРС после витрификаци, является снижение гиперосмотического стресса за счет уменьшения концентрации проникающих криопротекторов в растворе эквилибрации.

Введение. Витрификация является наиболее перспективным методом криоконсервации ооцитов крупного рогатого скота (КРС). Несмотря на начальный успех витрификации дозревших in vitro ооцитов коров [8] и значительное количество предлагаемых методик, на данный момент не существует единого протокола, обеспечивающего высокую стабильную жизнеспособность витрифицированных ооцитов [9]. Одно из решений данной проблемы заключается в применении принципа витрификации в минимальном объеме, а также в упрощении и стандартизации процедур витрифкации/ отогревания групп ооцитов, что может быть осущест- 
цетатцеллюлозных полых волокнах [6]. Однако в наших предыдущих исследованиях было показано, что полупроницаемая стенка волокна, отделяющая биологические объекты от растворов витрификации/отогревания, может влиять на жизнеспособность как интактных, так и лишенных блестящей оболочки эмбрионов КРС при различной продолжительности обработки $[1,5]$.

Одной из проблем витрификации является потенциально летальный осмотический стресс, которому подвергаются клетки в растворах витрификации/отогревания, содержащих высокие концентрации проникающих и непроникающих криопротекторов [3]. Сжатие клеток в растворах с высокой осмолярностью сверх определенного порогового минимума в течение длительного времени также может приводить к запуску механизмов апоптоза [3]. В случае с ооцитами КРС эффективность обработки в растворах эквилибрации и витрификации также осложняется отсутствием в их плазматической мембране аквапоринов (в частности, AQP3), способных существенно ускорить диффузию воды и проникающих криопротекторов [2], большим размером самого ооцита (диаметр 110 мкм), а также токсичностью высоких концентраций проникающих криопротекторов (этиленгликоля и диметилсульфоксида) [7]. Одним из способов снизить влияние этих факторов на ооциты КРС является уменьшение концентрации проникающих криопротекторов в растворе эквилибрации с одновременным увеличением времени обработки [8, 9].

Цель данной работы - изучение влияния условий эквилибрации на жизнеспособность дозревших in vitro ооцитов крупного рогатого скота, витрифицированных в триацетатцеллюлозном полом волокне.

Методика исследований. Для проведения экспериментов использовали выделенные из антральных фолликулов яичников и дозревшие in vitro ооциты КРС. Перед началом обработки ооциты освобождали от клеток кумулюса в растворе гиалуронидазы (1,1 мг/мл).

Процедуры витрификации/отогревания проводили в соответствии с работой H. Matsunari et al. [6] с рядом модификаций. В качестве носителя для витрификации использовали полупроницаемые триацетатцеллюлозные полые волокна с внутренним диаметром 200 мкм, толщиной стенок 15 мкм и размером пор 7 нм (Nirpo, Япония). В качестве основы для приготовления растворов витрификации и отогревания ооцитов использовали дополненную 20 \% сыворотки крови среду TLP-HEPES, приготовленную с добавлением (TH20) или без добавления $\mathrm{CaCl}_{2}$ (ТН20-). В качестве криопротекторов в растворах эквилибрации и витрификации использовали диметилсульфоксид (ДМСО) и/или этиленгликоль (ЭГ), а также сахарозу. Денудированные ооциты группами по 10-15 шт. последовательно инкубировали в двух сменах среды ТН20 или ТН20в течение 5 мин. Затем ооциты обрабатывали в растворах эквилибрации и витрификации в соответствии с одним из трех протоколов (табл. 1).

Аспирацию группы ооцитов в полое волокно проводили в растворе эквилибрации. Полое волокно с ооцитами в дальнейшем перемещали из раствора в раствор при помощи пинцета. После обработки в растворе витрификации волокно погружали в жидкий азот. При проведении отогревания полое волокно с ооцитами извлекали из жидкого азота и немедленно погружали в раствор отогревания, содержащий 0,5 M сахарозы, на 1 мин. Затем волокно с ооцитами последовательно
Состав растворов эквилибрации и витрификации и схема обработки ооцитов

\begin{tabular}{|c|c|c|c|c|c|}
\hline \multirow[b]{2}{*}{ 岂 } & \multirow[b]{2}{*}{$\begin{array}{c}\text { Базовая } \\
\text { среда }\end{array}$} & \multicolumn{2}{|c|}{ Раствор эквилибрации } & \multicolumn{2}{|c|}{ Раствор витрификации } \\
\hline & & \begin{tabular}{|c|} 
концентрация \\
криопротек- \\
торов (v/v) \\
\end{tabular} & $\begin{array}{c}\text { время } \\
\text { инкуба- } \\
\text { ции, мин } \\
\end{array}$ & \begin{tabular}{|c|} 
концентрация \\
криопротек- \\
торов
\end{tabular} & $\begin{array}{c}\text { время } \\
\text { инкуба- } \\
\text { ции, мин }\end{array}$ \\
\hline 1 & TH20 & $\begin{array}{l}\text { 7,5 \% ЭГ } \\
\text { 7,5 \% ДМСО }\end{array}$ & 5 & \begin{tabular}{|l|}
15,0 \% ЭГ \\
$15,0 \%$ ДМСО \\
0,5 М сахарозы
\end{tabular} & 1 \\
\hline 2 & TH20 & $\begin{array}{l}2,5 \% \text { ЭГ } \\
2,5 \% \text { ДМСО }\end{array}$ & 15 & \begin{tabular}{|l|}
15,0 \% ЭГ \\
$15,0 \%$ ДМСО \\
0,5 М сахарозы
\end{tabular} & 1 \\
\hline 3 & TH20- & $3,0 \%$ ЭГ & 15 & $\begin{array}{l}30,0 \text { \% ЭГ } \\
0,5 \text { М сахарозы }\end{array}$ & 1 \\
\hline
\end{tabular}

инкубировали в растворе разбавления с 0,25 M сахарозы в течение 3 мин и в двух сменах базовой среды по 5 мин в каждой. Ооциты из волокон извлекали в последней смене ТН20- и помещали в среду 199 на 2 ч. Все растворы, кроме раствора отогревания, использовали при комнатной температуре $\left(22-24^{\circ} \mathrm{C}\right)$. Отогревание проводили при температуре $39{ }^{\circ} \mathrm{C}$. В качестве контроля использовали денудированные дозревшие in vitro ооциты, не подвергавшиеся витрификации. Диаметр ооцитов без учета блестящей оболочки измеряли при помощи окуляр-микрометра под инвертированным микроскопом (X10) перед помещением в среду эквилибрации (T1), через 1, 5, 10 и 15 мин после начала эквилибрации (Т2, Т3, Т4, Т5), а также перед помещением отогретых ооцитов в среду 199 (Т6).

Для оплодотворения использовали сперматозоиды, выделенные из криоконсервированного семени быка

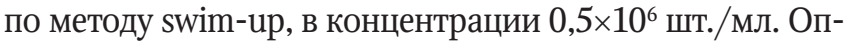
лодотворение проводили в среде TALP-Fert в течение 19 ч в $\mathrm{CO}_{2}$-инкубаторе при температуре $38,5^{\circ} \mathrm{C}$. Через 19 ч после начала оплодотворения (21 ч после отогревания) оценивали уровень выживания предполагаемых зигот по их морфологии, в частности по целостности плазматической мембраны. Затем зиготы культивировали в среде SOF в течение 25-27 ч, после чего оценивали дробление эмбрионов. Результаты представлены в виде среднего диаметра ооцитов \pm стандартное отклонение. Процент выживших и продробившихся эмбрионов вычисляли от общего количества витрифицированных ооцитов. Для статистического анализа полученных результатов использовали прараметрический $\mathrm{t}$-критерий Стьюдента $(p<0,05)$ или непараметрический критерий хи-квадрат Пирсона $(p<0,05)$.

Результаты исследований. Через 1 мин после погружения ооцитов в раствор эквилибрации наблюдалось уменьшение диметра ооцитов на 11,8 \% в группе 1 и на 3,3 \% в группах 2 и 3 (табл. 2). В свою очередь это означает снижение в точке Т2 относительного объема клеток в группе 1 приблизительно на $30 \%$, тогда как в группах 2 и 3 - только на 9-10\%. К концу эквилибрации (точка Т3 для группы 1 или T5 для групп 2 и 3) диаметр ооцитов восстанавливался. При этом динамика восстановления указывала на то, что время эквилибрации в протоколах групп 2 и 3 может быть в дальнейшем сокращено до 5-10 мин.

Наибольшее, но при этом кратковременное, сжатие происходит при обработке ооцитов в растворе витрификации. Затем, после помещения в раствор отогревания и последующие растворы, происходит постепенное восстановление диаметра и соответственно объема ооцитов. К моменту извлечения ооцитов из полого волокна (точка Т6) их диаметр во всех эксперименталь- 
Динамика изменения диаметра дозревших in vitro ооцитов под воздействием растворов эквилибрации разного состава

\begin{tabular}{|c|c|c|c|c|c|c|c|}
\hline Группа & Количество ооцитов & $\mathrm{T} 1$ & $\mathrm{~T} 2$ & $\mathrm{~T} 3$ & $\mathrm{~T} 4$ & T5 & T6 \\
\hline \multicolumn{8}{|c|}{ Средний диаметр ооцитов, мкм } \\
\hline 1 & 13 & $112,96 \pm 4,58$ & $99,63 \pm 4,98 *$ & $111,18 \pm 3,12$ & - & - & $113,16 \pm 3,77$ \\
\hline 2 & 21 & $116,78 \pm 3,77$ & $112,95 \pm 3,75^{*}$ & $117,03 \pm 4,15$ & $116,95 \pm 4,23$ & $117,79 \pm 4,07$ & $116,23 \pm 2,59$ \\
\hline 3 & 23 & $114,47 \pm 3,41$ & $110,71 \pm 5,25^{*}$ & $114,93 \pm 4,17$ & $115,56 \pm 3,94$ & $115,56 \pm 3,94$ & $114,28 \pm 3,03$ \\
\hline \multicolumn{8}{|c|}{ Относительный диаметр ооцитов } \\
\hline 1 & 13 & 1,000 & 0,882 & 0,984 & - & - & 1,002 \\
\hline 2 & 21 & 1,000 & 0,967 & 1,002 & 1,002 & 1,009 & 0,995 \\
\hline 3 & 23 & 1,000 & 0,967 & 1,004 & 1,009 & 1,012 & 0,998 \\
\hline
\end{tabular}

* статистически значимое отличие от Т1 ( $t$-критерий Стьюдента, $p<0,05)$.

ных группах достигал своих первоначальных значений вне зависимости от режима обработки в растворе эквилибрации. При этом во время проведения ооцитов в волокне через растворы отогревания не наблюдалось повторного сжатия клеток, которое, согласно некоторым литературным данным, может приводить к снижению уровня выживания ооцитов и компетенции к развитию полученных из них эмбрионов $[8,9]$.

Показатели выживания зигот, полученных после оплодотворения витрифицированных ооцитов, во всех экспериментальных группах уступали контрольным (хи-квадрат Пирсона, $p<0,05$ ), табл. 3. Однако снижение концентрации криопротекторов в растворе эквилибрации до 2,5 \% ДМСО и 2,5 \% ЭГ (группа 2) или до 3 \% ЭГ (группа 3) позволило существенно повысить выживаемость. Схожая тенденция наблюдалось и в случае с показателями дробления (см. табл. 3). Таким образом, протокол группы 1, ранее успешно использовавшийся для витрификации бластоцист КРС в полых волокнах [5], оказался наименее пригодным для работы с дозревшими in vitro ооцитами.

Таблица 3

\begin{abstract}
Выживание и дробление эмбрионов, полученных в результате оплодотворения витрифицированных/ отогретых ооцитов крупного рогатого скота
\end{abstract}

\begin{tabular}{|c|c|c|c|}
\hline Группа & $\begin{array}{c}\text { Количество } \\
\text { ооцитов }\end{array}$ & Выживание $n, \%$ & Дробление $n, \%$ \\
\hline Контроль & 72 & $68(94,44)$ & $43(59,72)$ \\
\hline 1 & 26 & $10(38,46)^{*}$ & $4(15,38)^{*}$ \\
\hline 2 & 65 & $54(83,08)^{* *}$ & $32(49,23)$ \\
\hline 3 & 77 & $63(81,82)^{* *}$ & $29(37,66)^{*}$ \\
\hline
\end{tabular}

* статистически значимое отличие от контроля (хи-квадрат Пирсона, $p<0,05)$; ** статистически значимое отличие от контроля и группы 1 (хи-квадрат Пирсона, $p<0,05$ ).

Как ЭГ, так и ДМСО в высоких концентрациях вызывают повышение концентрации ионов $\mathrm{Ca}^{2+}$ в ооплазме, что может приводить к нарушению процессов мейоза, оплодотворения и развития преимплантационного эмбриона [7]. При этом негативный эффект ЭГ снижается при удалении из инкубационной среды ионов $\mathrm{Ca}^{2+}$ и снижении концентрации самого ЭГ [4]. Воздействие ДМСО приводит к повышению концентрации $\mathrm{Ca}^{2+}$ в ооплазме за счет выхода ионов из эндоплазматического ретикулума и не зависит от их наличия или отсутствия в окружающей ооцит среде [4]. В нашем случае использование базовой среды со сниженным содержанием ионов $\mathrm{Ca}^{2+}$ (ТН20-) в сочетании с низким содержанием ЭГ (3\%) в растворе эквилибрации не приводило к улучшению жизнеспособности витрифицированных ооцитов и полученных из них эмбрионов (группа 3, см. табл. 3) по сравнению с общим снижением концентрации проникающих криопротекторов в растворе эквилибрации (группа 2, см. табл. 3). В целом в рамках данной работы были получены первые положительные результаты по витрификации дозревших in vitro ооцитов КРС в триацетатцеллюлозных полых волокнах.

Заключение. После оплодотворения витрифицированных ооцитов КРС наиболее низкие показатели выживания и дробления эмбрионов были получены при использовании протокола с наибольшей концентрацией проникающих криопротекторов (7,5 \% ДМСО и 7,5 \% ЭГ) в растворе эквилибрации, который успешно применялся для витрификации преимплантационных эмбрионов КРС в наших предыдущих исследованиях [5]. Полученные результаты свидетельствуют, что одним из факторов, положительно влияющих на выживание ооцитов КРС после витрификации в полых волокнах, является снижение гиперосмотического стресса в процессе эквилибрации.

Для оптимизации протокола витрификации дозревших in vitro ооцитов КРС в триацетатцеллюлозных полых волокнах требуются дальнейшие исследования.

\section{СПИСОК ЛИТЕРАТУРЫ}

1. Витрификация эмбрионов крупного рогатого скота без блестящей оболочки в триацетат целлюлозном полом волокне / Е.В. Корниенко [и др.] // Ветеринария, зоотехния и биотехнология. - 2017. - № 12. - С. 35-44.

2. Jin B., Kawai Y., Hara T., Takeda S., Seki S., Nakata Y., Matsukawa K., Koshimoto C., Kasai M., Edashige K. Pathway for the movement of water and cryoprotectants in bovine oocytes and embryos // Biology of Reproduction, 2011, Vol. 85, No. 4, P. 834-847.

3. Lai D., Ding J., Smith G.W., Smith G.D., Takayama S. Slow and steady cell shrinkage reduces osmotic stress in bovine and murine oocyte and zygote vitrification // Human Reproduction, 2014, Vol. 30, No. 1, P. 37-45.

4. Larman M.G., Sheehan C.B., Gardner D.K. Calcium-free vitrification reduces cryoprotectant-induced zona pellucida hardening and increases fertilization rates in mouse oocytes. // Reproduction, 2006, Vol. 131, No. 1, P. 53-61.

5. Malenko G.P., Kornienko E.V., Nesterov, I.I., Kosovsky G.Y. A new simple and reliable vitrification device based on Hollow Fiber Vitrification (HFV) method evaluated using IVP bovine embryos // Animal Reproduction, 2017, Vol. 14, No. 2, P. 392-399.

6. Matsunari H., Maehara M., Nakano K., Ikezawa Y., Hagiwara Y., Sasayama N., Nagashima H. Hollow fiber vitrification: A novel method for vitrifying multiple embryos in a single device // Journal of Reproduction and Development, 2012, Vol. 58, No. 5, P. 599-608.

7. Moussa M., Shu J., Zhang X., Zeng F. Cryopreservation of mammalian oocytes and embryos: current problems and future perspectives // Science China Life Sciences, 2014, Vol. 57, No. 9, P. 903-914.

8. Papis K., Shimizu M., Izaike Y. The effect of gentle pre-equilibration on survival and development rates of bo- 
vine in vitro matured oocytes vitrified in droplets // Theriogenology, 1999, Vol. 51, P. 173.

9. Papis K., Stachowiak E., Duda A., Ajduk A., Modliński J.A. Bovine oocyte in vitro maturation and cryopreservation: mirage or reality // Slovak Journal of Animal Science, 2015, Vol. 48, No. 4, P. 163-171.

Маленко Галина Петровна, $\partial-p$ биол. наук, зав. отделом экспериментальной эмбриологии, ФГБНУ Центр экспериментальной эмбриологии и репродуктивных биотехнологий. Россия.

Романова Анастасия Борисовна, младший научный сотрудник отдела экспериментальной эмбриологии, ФГБНУ Центр экспериментальной эмбриологии и репродуктивных биотехнологий. Россия.
Бригида Артем Владимирович, зав. отделом экспериментальной трансплантологии, ФГБНУ Центр экспериментальной эмбриологии и репродуктивных биотехнологий. Россия.

Корниенко Екатерина Валерьевна, научный сотрудник отдела экспериментальной эмбриологии, ФГБНУ Центр экспериментальной эмбриологии и репродуктивных биотехнологий. Россия.

127422, г. Москва, ул. Костякова, 12, стр. 4.

Тел.: + 79099017805 .

Ключевые слова: ооцит; витрификация; крупный рогатый скот; триацетатцеллюлозные полые волокна.

\title{
THE EFFECT OF EQUILIBRATION CONDITIONS ON THE VIABILITY OF VITRIFIED BOVINE OOCYTES OF COWS
}

Malenko Galina Petrovna, Doctor of Biological Sciences, Head of the Department of experimental embryology, Centre of Experimental Embryology and Reproductive Biotechnology. Russia.

Romanova Anastasia Borisovna, Junior Researcher of the Department of experimental embryology, Centre of Experimental Embryology and Reproductive Biotechnology. Russia.

Brigida Artem Vladimirovich, Head of the Department of experimental transplantology, Centre of Experimental Embryology and Reproductive Biotechnology. Russia.

Kornienko Ekaterina Valerievna, Researcher of the Department of of experimental embryology, Centre of Experimental Embryology and Reproductive Biotechnology. Russia.
Keywords: oocyte; vitrification; bovine; triacetate cellulose hollow fibers.

The effect of the equilibration conditions on the viability of in vitro matured bovine oocytes after vitrification in triacetate cellulose hollow fibers was evaluated in the current work. Results show that one of the factors impacting survival rates of vitrified bovine oocytes is the reduction of hyperosmotic strass by the means of decreasing of cryoprotectant concentration in equilibration solution.

DOI

удк 633,$31 ; 631,452 ; 631,582$

\section{ВЛИЯНИЕ МНОГОЛЕТНИХ КОРМОВЫХ КУЛЬТУР НА ПЛОДОРОДИЕ И ПРОДУКТИВНОСТЬ ПАШНИ В СПЕЦИАЛИЗИРОВАННЫХ ОРОШАЕМЫХ СЕВООБОРОТАХ}

\author{
МЕЛИХОВА Надежда Павловна, Всероссийский научно-исследовательский институт орошаемого \\ земледелия
}

ЗИБАРОВ Анатолий Александрович, Всероссийский научно-исследовательский институт орошаемого земледелия

ТЕГЕСОВ Дольган Сергеевич, Всероссийский научно-исследовательский институт орошаемого земледелия

Экспериментально подтверждено положительное влияние люцерны на урожайность сельскохозяйственных культур севооборотов, высеваемых по пласту и обороту пласта. Выявлено преимущество двух-, трехлетней люцерны в сравнении с иетырехлетней, после которой урожайность кукурузы снижалась на 11,6-15,9 \%, озимой пшеницы - на 15,721,6 \% в сравнении с менее долголетним ее использованием. Показано положительное влияние двух-, трехлетней люцерны на факторы плодородия почвы: агрофизические, агрохимические показатели, структурное состояние. Определена продуктивность гектара севооборотной пашни в зависимости от сроков пребывания на поле люцерны. Подтверждено положительное влияние многолетней люцерны на качество растениеводческой продукции в сравнении с однолетними злаково-бобовыми смесями. Результаты исследований показали, что необходимо включение многолетних бобовых культур (лючерны) в иередование культур севооборотов в иелях эффективного использования орошаемых земель.

Введение. Проблема правильного использования земли, ее сохранения и повышения плодородия почвы остается актуальной в условиях адаптивно-ландшафтной системы земледелия. В последнее время в результате снижения энергообеспеченности сельскохозяйственного производства, упрощения агротехнологий, сокращения объемов мелиорации и химизации произошло существенное снижение урожайности большинства сельскохозяйственных культур, продуктивности пашни, обострилась проблема плодородия почвы $[5,6,8]$.

В сложившихся условиях дестабилизации сельскохозяйственного производства возрастает значение биологических факторов интенсификации в растениеводстве, прежде всего культур севооборотов, в целях сохранения и повышения плодородия почвы $[1,3,7,9]$. Резервы интен- сификации использования пашни сводятся в основном к насыщению севооборотов адаптированными к почвенно-климатическим условиям высокопродуктивными культурами. В связи с этим для каждой природной зоны подбираются такие культуры, биологические особенности которых согласуются с внешними условиями среды произрастания. Каждая культура оценивается по хозяйственно ценным признакам, продуктивности, отзывчивости на орошение, адаптивности к агроландшафтным условиям [5, 6, 11-13].

Для повышения продуктивности поливного гектара необходимо откорректировать структуру посевов в направлении применения наиболее высокопродуктивных, энергонасыщенных и богатых белком культур. К их числу в условиях Волгоградской области кроме зернобо- 